\title{
Formation of a 2D Meta-stable Oxide by Differential Oxidation of AgCu Alloys
}

\author{
Kevin Schweinar,* Sebastian Beeg, Caroline Hartwig, Catherine R. Rajamathi, Olga Kasian, \\ Simone Piccinin, Mauricio J. Prieto, Liviu C. Tanase, Daniel M. Gottlob, Thomas Schmidt, Dierk Raabe, \\ Robert Schlögl, Baptiste Gault, Travis E. Jones, and Mark T. Greiner*
}

Cite This: ACS Appl. Mater. Interfaces 2020, 12, 23595-23605

Read Online

ACCESS | Lلll Metrics \& More | 回 Article Recommendations | (1) Supporting Information

ABSTRACT: Metal alloy catalysts can develop complex surface structures when exposed to reactive atmospheres. The structures of the resulting surfaces have intricate relationships with a myriad of factors, such as the affinity of the individual alloying elements to the components of the gas atmosphere and the bond strengths of the multitude of low-energy surface compounds that can be formed. Identifying the atomic structure of such surfaces is a prerequisite for establishing structure-property relationships, as well as for modeling such catalysts in ab initio calculations. Here, we show that an alloy, consisting of an oxophilic metal $(\mathrm{Cu})$ diluted into a noble metal $(\mathrm{Ag})$, forms a meta-stable twodimensional oxide monolayer, when the alloy is subjected to oxidative reaction conditions. The presence of this oxide is correlated with selectivity in the corresponding test reaction of ethylene epoxidation. In the present study, using a combination of in situ, ex situ, and theoretical methods (NAP-XPS, XPEEM, LEED, and DFT), we determine the structure to

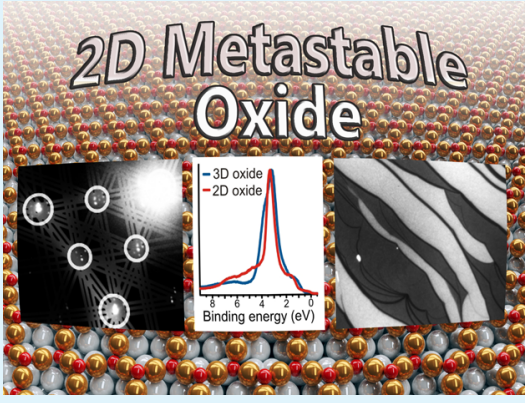
be a two-dimensional analogue of $\mathrm{Cu}_{2} \mathrm{O}$, resembling a single lattice plane of $\mathrm{Cu}_{2} \mathrm{O}$. The overlayer holds a pseudo-epitaxial relationship with the underlying noble metal. Spectroscopic evidence shows that the oxide's electronic structure is qualitatively distinct from its three-dimensional counterpart, and because of weak electronic coupling with the underlying noble metal, it exhibits metallic properties. These findings provide precise details of this peculiar structure and valuable insights into how alloying can enhance catalytic properties.

KEYWORDS: oxide monolayer, dilute alloy, meta-stable, XPS, 2-dimensional material

\section{INTRODUCTION}

1.1. Overview. One major difficulty in contemporary catalysis research is bridging the so-called "complexity gap". The complexity gap refers to the fact that catalysts used in applications of interest are much more complex entities than the model systems for which we are able to obtain precise atomic-scale detail in fundamental studies. For instance, subjecting a material to the conditions of industrial catalysts can give rise to the formation of a multitude of chemical phases, any of which could potentially play a role in catalysis, but remain unknown to us from model investigations. In order to accurately model catalysts in reactive conditions-for instance, to calculate adsorption energies and reaction barriers for use in micro-kinetic simulations-we require accurate knowledge of surface structures present in reaction conditions.

Much progress has been made in recent years to bridge the complexity gap, with the development of numerous in situ characterization methods. Unfortunately, it is often the case that one must sacrifice precision for in situ measurements. For instance, commonly used near-ambient pressure X-ray photoelectron spectroscopy (XPS) setups probe tens to hundreds of square microns of the sample surface to maximize the signal-tonoise ratio. However, the collected signal reflects an average of the probed area, which in turn prevents the spatial differentiation and unequivocal identification of localized phases. Consequently, one is often left with uncertain and ambiguous information about one's sample. In the present work, we bridge part of the complexity gap by combining several in situ, ex situ, and theoretical methods to identify a unique structure that forms on an alloy in a reactive gas atmosphere.

Metal alloys hold potential for developing novel catalysts. Under reaction conditions, synergies can arise between alloying elements to result in improved catalytic properties compared to the pure constituent metals. Heating an alloy in a reactive gas atmosphere can result in surface restructuring, phase segregation, preferential oxidation, and the formation of unique surface-adsorbate superstructures. Much theoretical effort has been devoted to predicting which alloy compositions

Received: March 5, 2020

Accepted: April 21, 2020

Published: April 21, 2020 
exhibit enhanced catalytic properties; ${ }^{1,2}$ however, without knowledge of the structures formed when exposing an alloy to reaction conditions, one is likely to overlook some important aspects.

A common strategy for predicting surface structures in reactive atmospheres is to propose candidate structures and use ab-initio thermodynamics to calculate their stabilities in a given atmosphere. ${ }^{3}$ The greatest difficulty here is choosing the candidate structures because the configurational space of all possible structures is far too large to test them all. Typical approaches for choosing candidate structures include a "chemical intuition", where one selects structural motifs known to exist from X-ray diffraction data or ultra-high vacuum surface science studies. Another approach is to generate candidate structures using genetic algorithms. In any case, there is no guarantee that the true surface structure was among the candidate structures tested, and experimental verification is the only way to determine which structures actually form, making such data extremely valuable for reaction pathway calculations.

Here, we take a closer look at a bimetallic alloy, consisting of an oxophilic metal $(\mathrm{Cu})$ and a noble metal $(\mathrm{Ag})$. In particular, we assess the (electronic) structure of the surface oxide that forms, when the alloy is exposed to an oxygen-containing reaction atmosphere. Previous reports have shown that the oxophilic element diffuses to the surface to form an unknown oxidic surface structure that is correlated with selectivity for the epoxidation reaction. ${ }^{4-6}$ In this contribution, we employ a suite of in situ techniques, with pressures ranging from $10^{-1}$ to $10^{-5}$ mbar. We show how it is possible to bridge part of the complexity gap by linking several datasets through shared attributes. The approach involves (1) characterizing spectroscopic properties using near-ambient pressure XPS (NAPXPS) and near edge X-ray absorption fine structure (NEXAFS) measurements; (2) identifying spectroscopic fingerprints that are correlated with epoxide selectivity; (3) characterizing the structure by means of X-ray photoemission electron microscopy (XPEEM) and low-energy electron diffraction (LEED), and verifying that the spectroscopic fingerprints observed under in situ NAP conditions, are also observed under XPEEM conditions; and (4) comparing the measured structural and spectroscopic data with simulated data from the candidate structures.

Using this approach, we determine the previously found mystery phase as a two-dimensional meta-stable $\mathrm{Cu}$-oxide, structurally analogous to a single lattice plane of $\mathrm{Cu}_{2} \mathrm{O}$, as depicted in Figure 1. Our findings provide valuable insights into the kinds of structures that can form on alloy catalysts.

\section{MATERIALS AND METHODS}

2.1. Experimental Section. Environmental scanning electron microscopy (ESEM) experiments were performed in a FEI Quanta

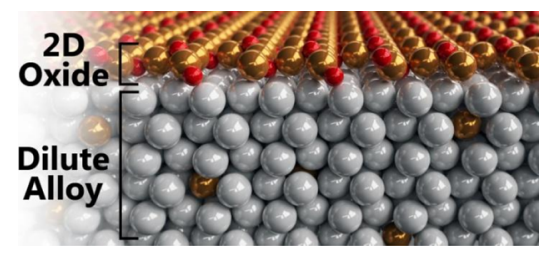

Figure 1. Rendition of the $\mathrm{Cu}_{x} \mathrm{O}_{y}$ structure formed on $\mathrm{AgCu}$ in oxidizing environments.
200 FEG, using a differentially pumped lens column and a gaseous secondary electron detector. Gases were continually flowed into the chamber via mass flow controllers to a pressure of $0.3 \mathrm{mbar}$. Sample heating was accomplished through an infrared laser fed into the chamber via a fiber-optics feed-through.

In situ NAP-XPS measurements were performed at the ISISS beamline at the synchrotron radiation facility BESSY II of the Helmholtz-Zentrum Berlin (HZB), using a differentially pumped Phoibos 150 hemispherical analyzer from Specs GmbH. The ISISS beamline is a dipole photon source, with a plane-grating monochromator, delivering $6 \times 10^{10}$ photons/s/0.1 A and an energy resolution of $>15000$ at $400 \mathrm{eV}$. NAP-XPS experiments were performed in a gas pressure of 0.3 mbar. Ethylene epoxidation conditions utilized a 1:1 mixture of $\mathrm{O}_{2} / \mathrm{C}_{2} \mathrm{H}_{4}$ with a total flow rate of $6 \mathrm{~mL} / \mathrm{min}$. Sample heating up to $250{ }^{\circ} \mathrm{C}$ was accomplished by illuminating the backside of the sample pellets with an infrared laser. The sample pellets were prepared following the procedure reported in ref 4. This experiment yields nonspatially resolved XPS ( $\mathrm{Cu} 2 \mathrm{p}, \mathrm{O} 1 \mathrm{~s}$, $\mathrm{Ag} 3 \mathrm{~d}$ ), NEXAFS ( $\mathrm{O} \mathrm{K}, \mathrm{Cu} \mathrm{L}$ ), and valence band spectra under conditions where ethylene epoxide is formed.

Low-energy electron microscopy (LEEM)/LEED and XPEEM measurements were carried out in the SMART spectro-microscope operating at the UE49-PGM beamline at the synchrotron radiation facility BESSY II of the HZB. The aberration-corrected and energyfiltered LEEM/PEEM instrument combines microscopy, diffraction, and spectroscopy techniques for comprehensive characterization. The instrument achieves an experimentally demonstrated lateral resolution of $2.6 \mathrm{~nm}$ in LEEM and $18 \mathrm{~nm}$ in energy-filtered XPEEM mode, respectively. ${ }^{7,8}$

We used a polycrystalline $\mathrm{AgCu}$ diffusion couple for our first experiment. The sample was prepared by fusing together a piece of high purity silver and copper. This couple was then annealed in $\mathrm{Ar}$ for $21 \mathrm{~h}$ at $750{ }^{\circ} \mathrm{C}$ before it was cut and mechanically ion polished. A single crystalline $\mathrm{AgCu}(111)$ surface was used for the second XPEEM experiment.

The $\mathrm{AgCu}(111)$ crystal was prepared by depositing a copper thin film of $50 \mathrm{~nm}$ thickness onto a $\mathrm{Ag}(111)$ crystal by physical vapor deposition. The crystal was then annealed in $\mathrm{H}_{2}$ inside a lab-source NAP-XPS system at temperatures from 100 to $630{ }^{\circ} \mathrm{C}$ while monitoring the $\mathrm{Cu} 2 \mathrm{p}$ signal (see Supporting Information S.1) and then annealed in $\mathrm{H}_{2}$ at $550{ }^{\circ} \mathrm{C}$ for additional $4 \mathrm{~h}$. The annealing procedure leads to $\mathrm{Cu}$ reduction and diffusion into the $\operatorname{Ag}(111)$ crystal.

The single crystal was transported in air from Mülheim an der Ruhr, Germany, to Berlin, Germany, one day after the annealing treatment. After loading the sample into the XPEEM microscope at the SMART beamline, the sample was sputtered with $\mathrm{Ar}^{+}(1.5 \mathrm{keV}$ ion energy, $0.06 \mu \mathrm{A}$ flux, for $15 \mathrm{~min})$ and annealed in UHV $\left(3 \times 10^{-9}\right.$ mbar) for $5 \mathrm{~min}$ at $400{ }^{\circ} \mathrm{C}$. Following this procedure, the surface of the sample was crystalline, but too rough for high-resolution imaging (see Supporting Information S.2-A). The sputter-annealing treatment was repeated 23 times until a contaminant-free and smooth surface was obtained (see S.2-B). The surface was then reduced by heating to $400{ }^{\circ} \mathrm{C}$ in $1 \times 10^{-5} \mathrm{mbar}_{2}$ for $10 \mathrm{~min}$. This resulted in a clean surface, free of oxidized copper species. The oxidation of the alloy was performed in $1 \times 10^{-5} \mathrm{mbar} \mathrm{O}_{2}$ at $300{ }^{\circ} \mathrm{C}$. These experiments yield spatially resolved XPS (O 1s, Cu 2p, Ag 3d), valence band spectra, microscopy images, and LEED patterns.

NAP-XPS measurements on the $\mathrm{AgCu}(111)$ single crystal were performed under identical conditions as the XPEEM experiments, prepared as described above. The measurements were carried out at the BelChem beamline of the synchrotron radiation facility BESSY II of the HZB, using a differentially pumped Phoibos 150 hemispherical analyzer from Specs $\mathrm{GmbH}$. The results from this method provide high quality and energy calibrated non-spatially resolved XPS (Cu 2p, $\mathrm{O} 1 \mathrm{~s}, \mathrm{Ag} 3 \mathrm{~d})$, Auger spectra (Cu LMM), NEXAFS ( $\mathrm{O} \mathrm{K}, \mathrm{Cu} \mathrm{L})$, and valence band spectra.

The density functional theory (DFT) calculations were performed using the Heyd-Scuseria-Ernzerhof HSE06 exchange and correlation functional. ${ }^{9}$ We used optimized norm-conserving Vanderbilt 

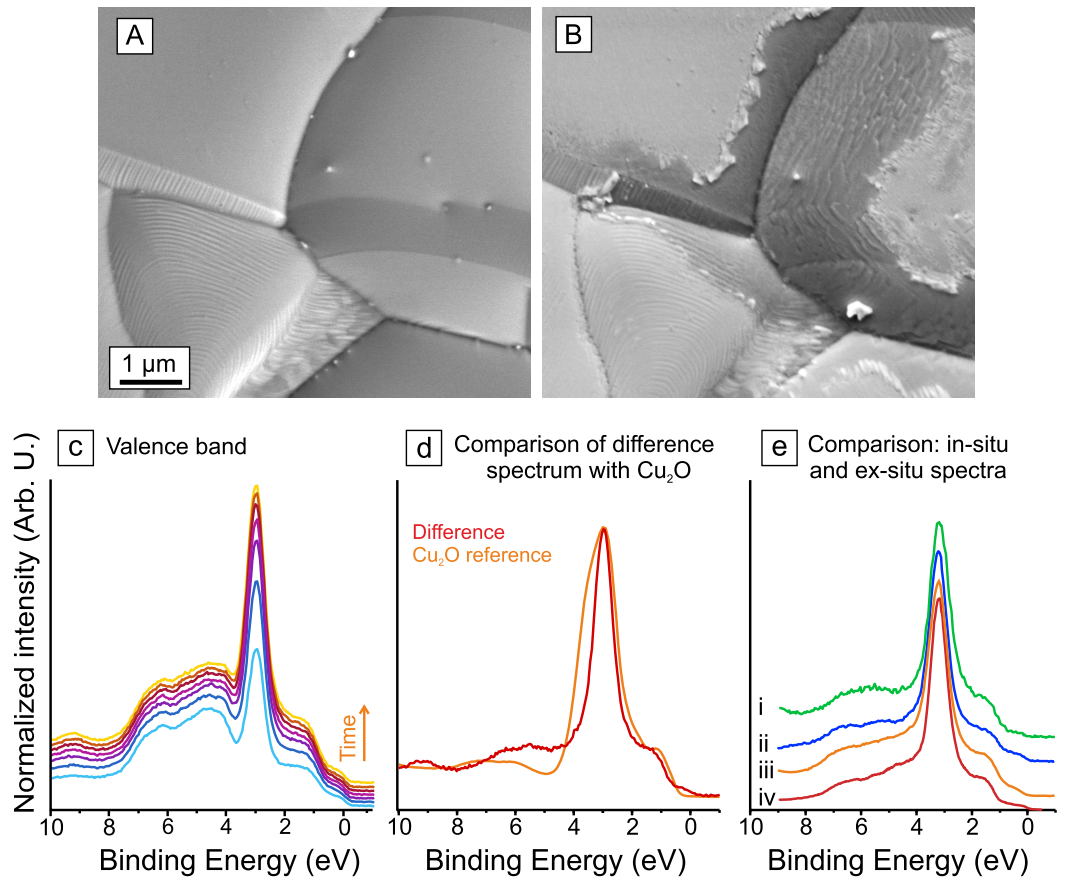

Figure 2. ESEM images of $(\mathrm{A})$ a reduced $\mathrm{AgCu}$ foil $(0.5$ at. $\% \mathrm{Cu})$ and $(\mathrm{B})$ the same foil while heated in 0.3 mbar ethylene and oxygen at $300{ }^{\circ} \mathrm{C}$. (C) In situ NAP-XPS valence spectra $(h \nu=150 \mathrm{eV})$ measured as a time series under epoxidation conditions (time step = $50 \mathrm{~min}, 0.3 \mathrm{mbar}, 1: 1$ $\mathrm{O}_{2} / \mathrm{C}_{2} \mathrm{H}_{4}, 300 \mathrm{C}$ ). (D) Comparison of a difference spectrum generated (see Supporting Information for details) with a reference spectrum of $\mathrm{Cu}_{2} \mathrm{O}$. (E) Comparison of several in situ measurements, using a Phoibos NAP-150 analyzer (i-iii) with a measurement performed in ultra-highvacuum, using an XPEEM analyzer (iv). Spectra $i$ and ii are measured in 0.5 mbar of a 1:1 mixture of ethylene and oxygen. Spectrum (iii) is measured in 0.5 mbar of a dilute $-\mathrm{O}_{2}$ mixture containing 1:50 mixture of oxygen to ethylene. Spectrum (iv) is measured on a $\mathrm{AgCu}(111)$ single crystal at $300{ }^{\circ} \mathrm{C}$ in $1 \times 10^{-5} \mathrm{mbar}_{2}$.

(ONCV), with a plane wave cutoff of $60 \mathrm{Ry}$. The surface oxides were formed on top of a $\operatorname{Ag}(111)$ surface, modelled using a 4-layer slab, sampling the Brillouin zone with $K$-point grids equivalent to a $12 \times 12$ $\times 1$ on the $1 \times 1$ surface unit cell and broadening the Fermi surface using the Marzari-Vanderbilt scheme with a 0.04 Ry smearing energy. During the structural optimizations, the bottom two layers of the Ag slabs were kept fixed to bulk atomic positions. The starting geometries were taken from the work of Piccinin et al. ${ }^{10}$ and further optimized, until forces were smaller than $0.026 \mathrm{eV} / \AA$. All the calculations were performed with the Quantum ESPRESSO code. ${ }^{11}$ The DFT calculations provide candidate structures, their energies, the density of states (DOS), and symmetry.

Each type of experiment provides a set of useful attributes that can be utilized to link the experiments together. A connectivity graph of the various kinds of data is provided in the Supporting Information (S.3). While the valence band, for instance, is an attribute that all experiments have in common, that is, that could be measured or calculated in every experiment, XPEEM, DFT, and NAP-XPS on the single crystal share the same experimental conditions. Figure $\mathrm{S} 3 \mathrm{H}$ shows the complete connectivity graph in which the line thickness represents the number of links that exists between the different experiments. By networking commonly observed data sets among different experiments, drawing a link between atomic structure of the investigated surface oxide and its function becomes possible.

2.2. Data Analysis. Spectromicroscopy stacks were generally measured by (1) choosing a fixed photon energy, (2) setting the microscope lens settings such that the surface image plane is focused on the 2D detector, (3) band-pass filtering the photoelectrons by kinetic energy, and (4) scanning the sample potential at fixed filter settings, while measuring the resulting $2 \mathrm{D}$ detector image. The result of this measurement is a stack of detector images, where each image represents the spatial distribution of photoelectrons having a given binding energy, as defined by the sample potential referring to the fixed band center used for the energy filter in the given image. An alternative way to view the data is a $2 \mathrm{D}$ array of photoemission spectra. The (uncropped) image size is $1600 \times 1200$ pixels, so that there are $1.92 \times 10^{6}$ photoemission spectra in a dataset. The detector pixels were binned to make images of $400 \times 300$ pixels. To identify how many chemical components were present in the image stack, we performed principle component analysis (PCA) and determined how many abstract factors were significant in relation to the image noise. After this procedure, we imaged regions appearing to be phase pure and generated basis vectors by summing the spectra in these homogeneous regions. These basis vectors were then used to fit the original 120000 spectra using linear least-squares regression, to give the result of a spatial map of the chosen basis vectors. Such maps are shown in Figures $3 \mathrm{c}, \mathrm{d}, 4 \mathrm{c}, \mathrm{d}$, and $5 \mathrm{a}$.

The XPS spectra were measured using the XPEEM instrument (SMART spectro-microscope) at the UE49-PGM beamline. They were measured by (1) choosing a photon energy, (2) in the LEEM mode, moving the sample such that the field-of-view is homogeneously covered by a single phase, and (3) setting the lenses such that the energy-dispersive plane is imaged onto the $2 \mathrm{D}$ detector. The resulting detector image represents binding energy (kinetic energy) along one direction and spatial dispersion along the perpendicular direction. A flat-field image was used to correct the variation in sensitivity across the detector. The spectra were summed along the spatial dispersive direction to give rise to a typical photoemission spectrum. This procedure was used for the spectra in Figures $3 b, 4 b$, $5 e, f$, and Figure 10 .

The XPS spectra measured in near-ambient pressure conditions (at the BelChem beamline) were measured using a Specs GmbH Phoibos $150-\mathrm{NAP}$ analyzer. In this process, (1) the photon energy was chosen, (2) the photon energy is calibrated by measuring the Fermi level, (3) electrons pass through a hemispherical analyzer holding a constant pass energy, thereby acting as a band-pass filter for electrons, (4) the photoelectrons strike a 140-channel 1D delay-line detector at the end of the hemisphere, (5) the kinetic energy of incoming electrons is ramped using a retarding potential, in the standard fixed-analyzertransmission mode, and (6) the detector channel representing count 

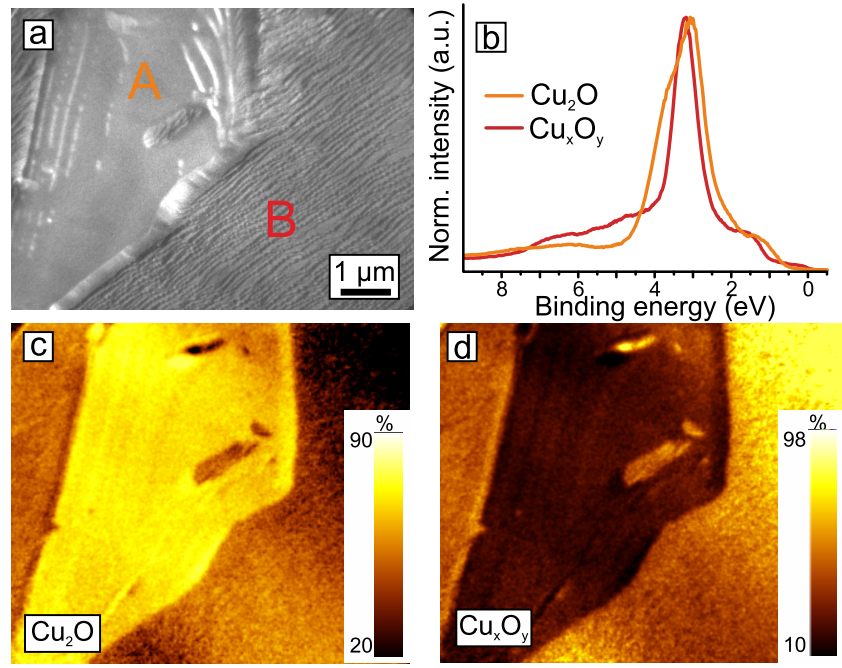

Figure 3. (a) LEEM image showing the coexistence of $\mathrm{Cu}_{2} \mathrm{O}(\mathrm{A})$ and $\mathrm{Cu}_{x} \mathrm{O}_{y}(\mathrm{~B})$ on a polycrystalline $\mathrm{AgCu}$ sample $\left(E_{\text {kin }}=4.8 \mathrm{eV}\right)$. (b) Valence band spectra $(h \nu=170)$ of regions A and B. $(c, d)$ Spatial distributions of $\mathrm{Cu}_{2} \mathrm{O}$ and $\mathrm{Cu}_{x} \mathrm{O}_{y}$ valence spectra, as determined from a XPEEM image stack.
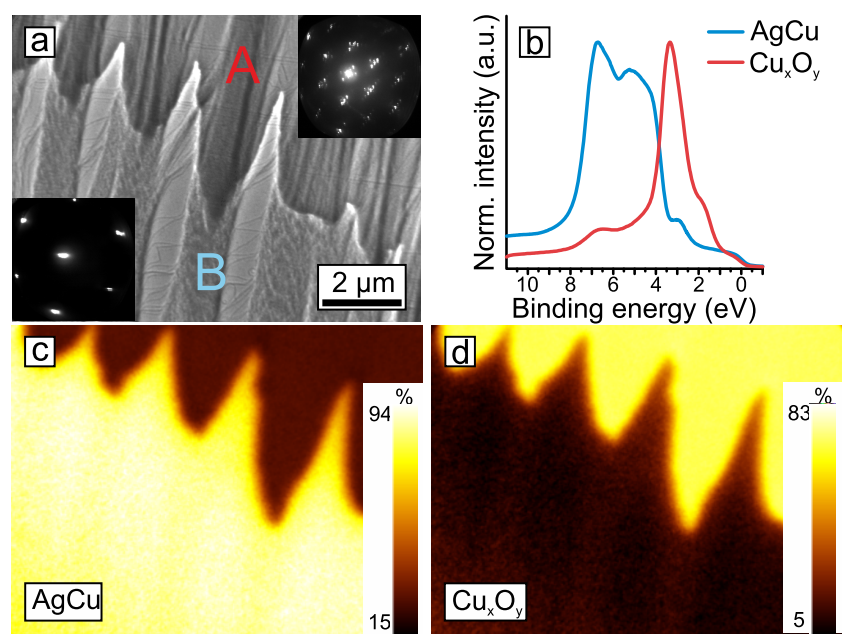

Figure 4. (a) LEEM image of a surface partially covered by $\mathrm{Cu}_{x} \mathrm{O}_{y}$ (region A), $E_{\text {kin }}=5 \mathrm{eV}$. The insets show the corresponding LEED patterns at $E_{\text {kin }}=42 \mathrm{eV}$. (b) Valence spectra from regions A and B in $(h \nu=170 \mathrm{eV}) .(\mathrm{c}, \mathrm{d})$ Spatial distributions of $\mathrm{AgCu}$ and $\mathrm{Cu}_{x} \mathrm{O}_{y}$ valence spectra, as determined from a XPEEM image stack.

rates for electrons having same kinetic energies are binned together. Such measurements result in XPS spectra as shown in Figures $2 c, d, e$, $5 e, f$, and 7.

The NEXAFS spectra were measured at the BelChem beamline. The spectra were measured by (1) scanning the photon energy across some range and (2) measuring the total electron yield by measuring the drain current at the nozzle of a Specs GmbH Phoibos 150-NAP analyzer, positioned $1 \mathrm{~mm}$ away from the sample surface.

\section{RESULTS}

3.1. Linking NAP-XPS with XPEEM. The AgCu alloy (0.5 at. \% $\mathrm{Cu}$ ) was first characterized using NAP-XPS and ESEM at conditions where ethylene epoxidation can occur (i.e. in a 1:1 mixture of ethylene and $\mathrm{O}_{2}$, at $300{ }^{\circ} \mathrm{C}$ ). Under these conditions, silver oxides are not stable, while copper oxides are, ${ }^{4,10,12}$ and consequently, $\mathrm{Cu}$ becomes preferentially oxidized, forming $\mathrm{Cu}$-containing oxides at the surface. For

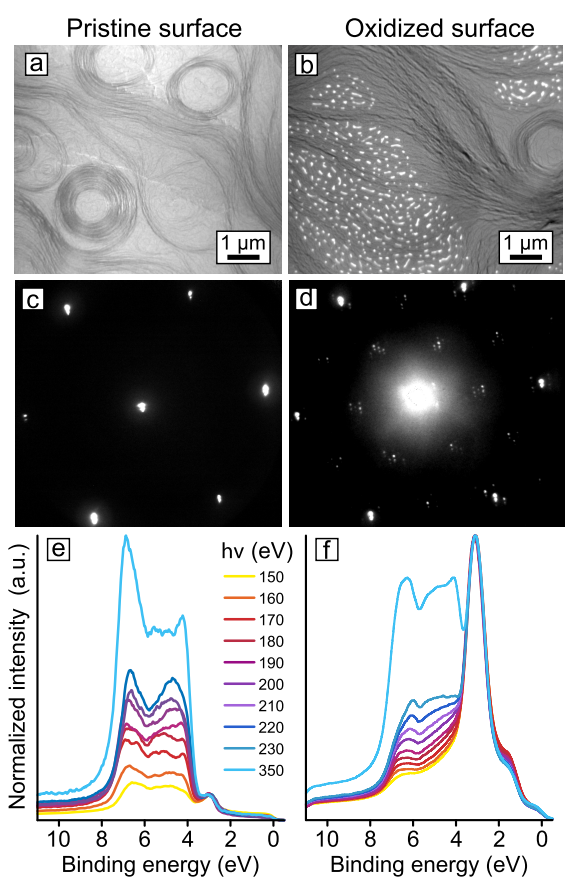

Figure 5. Comparison of the pristine (left column) and oxidized (right column) $\mathrm{AgCu}(111)$ surface. (a-c) LEEM image $\left(E_{\text {kin }}=42\right.$ $\mathrm{eV})$, LEED pattern $\left(E_{\text {kin }}=42 \mathrm{eV}\right)$, and $(\mathrm{d}-\mathrm{f})$ valence spectra at photon energies close to the Cooper minimum of $\mathrm{Ag} 4 \mathrm{~d}$.
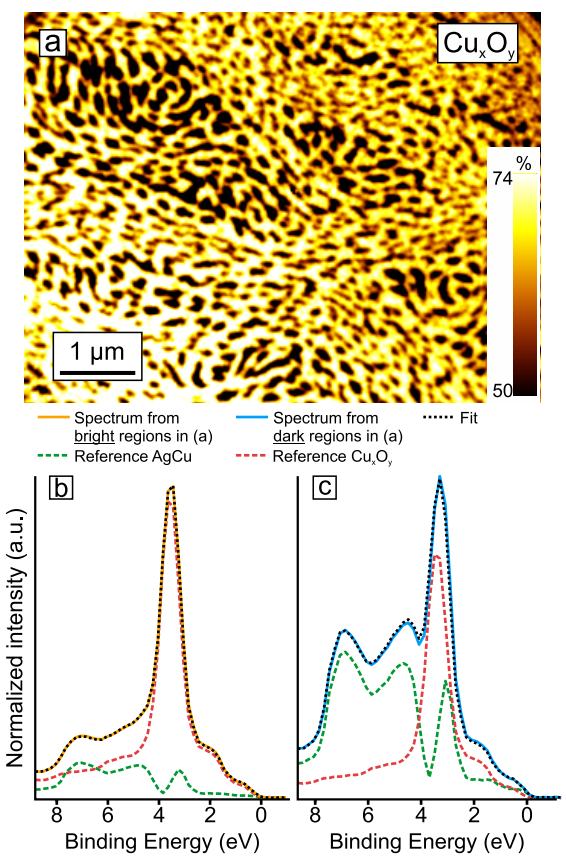

Figure 6. (a) Analyzed XPEEM valence band maps measured in $\mathrm{p}\left(\mathrm{O}_{2}\right)=1 \times 10^{-5} \mathrm{mbar}$ and $300{ }^{\circ} \mathrm{C}$ at a photon energy of $h \nu=170$ $\mathrm{eV}$. The map shows the spatial distribution of $\mathrm{Cu}_{x} \mathrm{O}_{y}$. The color scale represents the percentage of the reference spectrum used to fit the map. The corresponding summed spectra of the bright colored and dark colored regions in (a) are shown in $(b, c)$. Two components (i.e., reference metallic $\mathrm{AgCu}$ and reference $\mathrm{Cu}_{x} \mathrm{O}_{y}$ spectrum) are required to fit the data.

instance, Figure 2 shows ESEM images of a polycrystalline $\mathrm{AgCu}$ foil (0.5 at. \% $\mathrm{Cu}$ ) prior to (Figure $2 \mathrm{~A}$ ) and during (Figure 2B) ethylene epoxidation (conditions are $1: 1 \mathrm{C}_{2} \mathrm{H}_{4}$ / $\mathrm{O}_{2}, P_{\text {tot }}=0.3$ mbar at $300{ }^{\circ} \mathrm{C}$ ). One can see that, during 


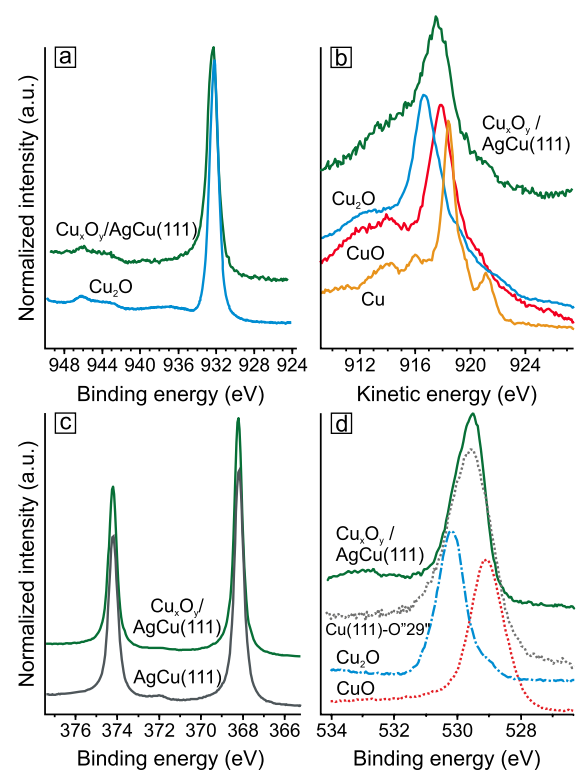

Figure 7. Comparison of photoemission spectra from $\mathrm{Cu}_{x} \mathrm{O}_{y} /$ $\operatorname{AgCu}(111)$ with reference spectra. (a) $\mathrm{Cu} 2 \mathrm{p}$ core level spectra. (b) Cu LMM Auger spectra. (c) $\mathrm{Ag} 3 \mathrm{~d}_{5 / 2}$ spectra and (d) $\mathrm{O} 1 \mathrm{~s}$ spectra.

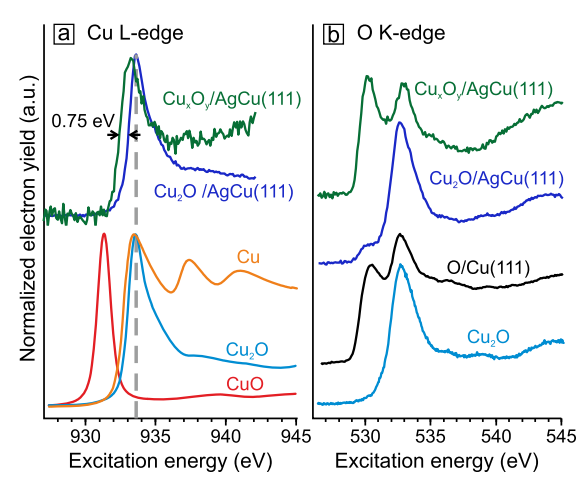

Figure 8. Experimental NEXAFS spectra of the $\mathrm{Cu}$ L-edge (a) and $\mathrm{O}$ K-edge (b) and reference spectra of similar structures $\left[\mathrm{Cu}, \mathrm{Cu}_{2} \mathrm{O}\right.$, $\mathrm{CuO}$, and $\mathrm{O} / \mathrm{Cu}(111)]$. The spectra containing $\mathrm{Cu}_{x} \mathrm{O}_{y} / \mathrm{AgCu}(111)$ were measured in an oxidizing atmosphere $\left(1 \times 10^{-5} \mathrm{mbar} \mathrm{O}_{2}, 300\right.$ $\left.{ }^{\circ} \mathrm{C}\right)$.

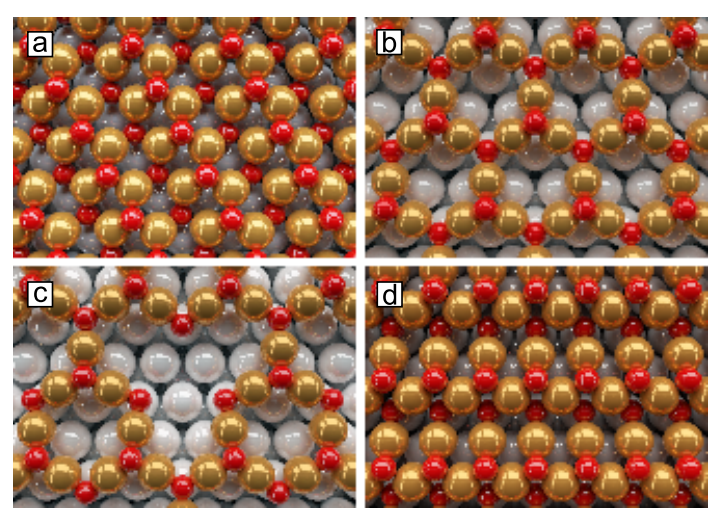

Figure 9. $3 \mathrm{D}$ models of proposed structured candidates. (a) Chemisorbed oxygen $\left(\mathrm{Cu}_{4} \mathrm{O}_{4}\right)$, (b) p2, (c) p4, and (d) CuO-1ML.

ethylene epoxidation, the surface becomes decorated with a variety of different copper-containing oxides, as evident from the various island morphologies and changes in contrast in Figure 2B (EDX maps are provided in Figure S17).

In situ valence band photoemission spectra (Figure 2C-E) give an indication of the identities of the oxides present on the surface. The valence band spectra reflect the electronic structure of a material (particularly, the occupied DOS) and can be used as a fingerprint to distinguish $\mathrm{CuO}, \mathrm{Cu}_{2} \mathrm{O}$, and metallic Ag. ${ }^{13,14}$ The valence band spectra of $\mathrm{AgCu}$ in epoxidation conditions (Figure 2C) show a signal that is a linear combination of several distinct valence band fingerprints. From a multivariate analysis of the spectrum stack in Figure $2 \mathrm{C}$, we find that the spectra are composed of spectra from several species (see analysis in Supporting Information), including a metallic $\mathrm{AgCu}$ signal and some unidentified species with a line shape similar but distinct from $\mathrm{Cu}_{2} \mathrm{O}$, as shown in Figure 2D. This species was previously shown to be correlated with epoxide selectivity. ${ }^{4}$ Figure $2 \mathrm{D}$ shows the spectrum of this unknown species after subtracting a portion of metal Ag signal from the mixed-signal spectrum. The resulting difference spectrum is plotted with a reference spectrum of $\mathrm{Cu}_{2} \mathrm{O}$ and exhibits distinct differences in line shape and position. These observations imply that a species is present on the surface, having an electronic structure similar to that of $\mathrm{Cu}_{2} \mathrm{O}$.

This information alone is not sufficient to determine the atomic structure of the unknown phase. To identify the phase, one needs to isolate it. However, the feature sizes of this phase are on the order of hundreds of nanometers (Figure 2B). To obtain a phase pure spectral signature, one requires spectroscopic methods with nanometer spatial resolution. To this end, we utilized XPEEM, with which one can obtain photoelectron spectra with a spatial resolution of ca. $20 \mathrm{~nm}$. Unfortunately, this method is not capable of measurements under the same conditions as NAP-XPS; so one must first verify that the signatures observed in NAP-XPS are also present under the conditions of XPEEM measurements.

As shown in Figure 2E, the spectroscopic features observed in situ could also be produced ex situ by heating a sputtercleaned alloy surface in $10^{-5} \mathrm{mbar}_{2}$. Figure $2 \mathrm{E}$ shows several examples of the oxide formed in situ, including (i) an $\mathrm{Ag}_{99.5} \mathrm{Cu}_{0.5}$ sample at $350{ }^{\circ} \mathrm{C}$ in 0.5 mbar mixture of $1: 1 \mathrm{O}_{2} /$ $\mathrm{C}_{2} \mathrm{H}_{4}$, (ii) an $\mathrm{Ag}_{98} \mathrm{Cu}_{2}$ sample at $350{ }^{\circ} \mathrm{C}$ in 0.5 mbar mixture of 1:1 $\mathrm{O}_{2} / \mathrm{C}_{2} \mathrm{H}_{4}$, and (iii) an $\mathrm{Ag}_{99.5} \mathrm{Cu}_{0.5}$ sample at $350{ }^{\circ} \mathrm{C}$ in a 1:50 mixture of $\mathrm{O}_{2} / \mathrm{C}_{2} \mathrm{H}_{4}$.

Figure 3 shows a LEEM image and XPEEM maps of a polycrystalline $\mathrm{AgCu}$ alloy after oxidation in $10^{-5} \mathrm{mbar}_{2}$. These images show a region of the surface where both $\mathrm{Cu}_{2} \mathrm{O}$ and the unknown phase are present. The $\mathrm{Cu}_{2} \mathrm{O}$ region is the island in the left half of the image (labeled A), as determined using spectro-microscopy image stacks. The image stacks represent a spatial map of the valence band spectra (measured using $h \nu=150 \mathrm{eV}$ ). The spectra extracted from the $\mathrm{Cu}_{2} \mathrm{O}$ region and unknown-phase region are shown in Figure $3 \mathrm{~b}$. These spectra were obtained by restricting the area-of-interest (AOI) of the spectrometer by using a field aperture, such that a single phase covers the entire AOI, and then measuring an XPS spectrum. Figure $3 \mathrm{c}$,d shows the spatial distribution of the two valence spectra $\left(\mathrm{Cu}_{2} \mathrm{O}\right.$ and $\left.\mathrm{Cu}_{x} \mathrm{O}_{y}\right)$. The data processing methods are explained in the Materials and Methods section.

The beauty of this data set is that the unknown structure and the reference structure $\left(\mathrm{Cu}_{2} \mathrm{O}\right)$ are both present in the same field of view, such that $\mathrm{Cu}_{2} \mathrm{O}$ acts as an internal standard. With this configuration, the subtle spectroscopic differences can be very accurately compared. We can see that the difference in 

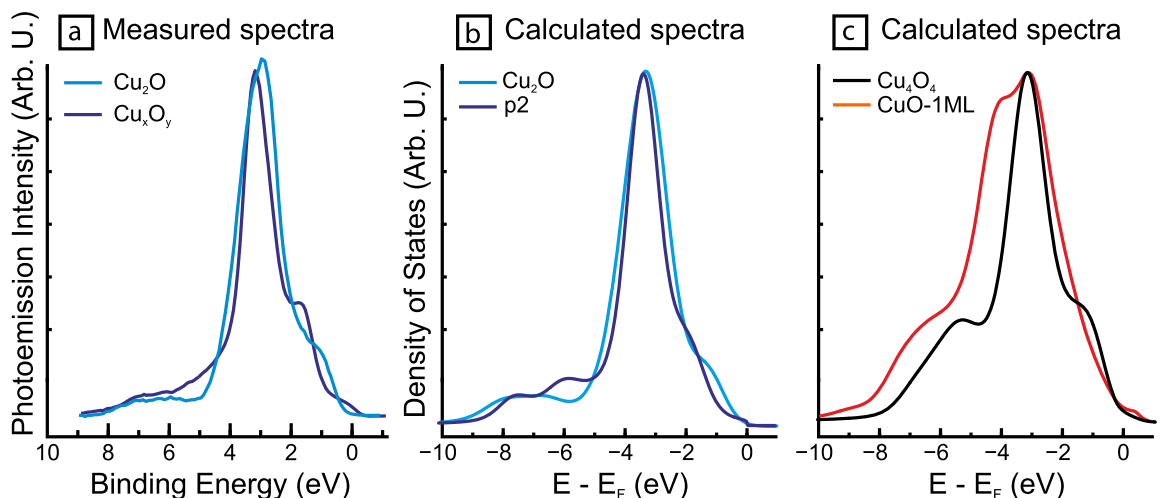

Figure 10. Comparison of (a) experimental valence band spectra of $\mathrm{Cu}_{2} \mathrm{O}$ (internal standard) and $\mathrm{Cu}_{x} \mathrm{O}_{y}$ measured at $h \nu=170 \mathrm{eV}$ and $(\mathrm{b}+\mathrm{c}$ ) DFT calculated DOS, weighted by their photoionization cross sections at $170 \mathrm{eV}, \mathrm{of} \mathrm{Cu}_{2} \mathrm{O}$ and the proposed structure candidates.

line shapes between $\mathrm{Cu}_{2} \mathrm{O}$ and the unknown phase observed under XPEEM conditions is qualitatively the same as what was observed during the NAP-XPS measurements (see Figure 2E), suggesting that the phases formed in NAP-XPS were also stable in the XPEEM instrument. From here on, we will refer to the unknown phase as $\mathrm{Cu}_{x} \mathrm{O}_{y}$.

The polycrystalline alloy surface oxidizes non-homogeneously, with the $\mathrm{Cu}_{x} \mathrm{O}_{y}$ phase covering large proportions (several tens of micrometers wide) of the surface, with the occasional appearance of $\mathrm{Cu}_{2} \mathrm{O}$ islands, typically similar in size to that shown in Figure 3. Through exploration of the surface, we found regions where no oxidation had occurred, and the surface was still metallic. Figure $4 a$ shows a LEEM image of such a region. Here, the $\mathrm{Cu}_{x} \mathrm{O}_{y}$ surface phase terminates, and the metallic $\mathrm{AgCu}$ surface is exposed.

The valence spectra in Figure $4 \mathrm{~b}$ clearly show the different valence structures of the two regions. The red and blue curves in Figure $4 \mathrm{~b}$ are the valence spectra from the regions labeled in Figure $4 \mathrm{a}$ as A and B, respectively. Figure $4 \mathrm{c}, \mathrm{d}$ show the spatial distributions of the two valence spectra, illustrating that region $\mathrm{A}$ is the $\mathrm{Cu}_{x} \mathrm{O}_{y}$ phase, and region $\mathrm{B}$ is the non-oxidized $\mathrm{AgCu}$ surface. LEED patterns of these regions reveal that the $\mathrm{AgCu}$ surface has a (111) termination, and the $\mathrm{Cu}_{x} \mathrm{O}_{y}$ has a pseudo$(2 \times 2)$ superstructure on the $(111)$ termination. Here, we use the prefix "pseudo" because, on close examination of the diffraction spots, one can distinguish a Moiré pattern, implying the overlayer's lattice parameter is either slightly larger or slightly smaller than that of the underlying metal lattice. A structural model for the surface is discussed in detail in Section 4.3.

3.2. Examination of $\mathrm{AgCu}(111)$. To better understand the structure of the $\mathrm{Cu}_{x} \mathrm{O}_{y}$ surface phase, we repeated the XPEEM measurements with a $\mathrm{AgCu}(111)$ single crystal. Using a single crystalline sample ensures more controlled sample conditions and avoids effects related to grain boundaries. The $\mathrm{Ag}(111)$ single crystal contained ca. 0.7 at. $\% \mathrm{Cu}$, as determined by a laboratory-based XPS (see Figure S1). Here we compare the LEEM, LEED, and valence spectra of the pristine $\mathrm{AgCu}(111)$ surface (after 23 consecutive sputterannealing cycles) with the same surface after oxidizing the sample in $1 \times 10^{-5} \mathrm{mbar}_{2}$ at $300{ }^{\circ} \mathrm{C}$ for $1 \mathrm{~h}$ inside the XPEEM analysis chamber.

As seen in the LEEM image in Figure 5a, the pristine $\mathrm{AgCu}(111)$ surface was relatively homogeneous, with flat terraces $1-2 \mu \mathrm{m}$ wide, with mono-atomic steps discernible as very fine lines on the terraces. The LEEM image after oxidation shows strong contrast, with localized bright features on the order of $\sim 100 \mathrm{~nm}$ in diameter covering the surface. As explained further with Figure 6, the bright features are metallic $\mathrm{AgCu}$, and the dark features are $\mathrm{Cu}_{x} \mathrm{O}_{y}$. These observations imply that a discontinuous mesh-like oxidic structure had formed over the surface.

From the LEED patterns in Figure $5 c-d$, one can clearly identify the three-fold symmetry of the pristine (111) oriented crystal. After oxidation, the LEED pattern shows a pseudo- $(2 \times$ 2) periodicity with respect to the $\operatorname{Ag}(111)$ surface, similar to the observation made on the oxidized polycrystalline $\mathrm{AgCu}$ alloy, shown in Figure 4a.

The valence spectra of the pristine and oxidized surfaces are shown in Figure 5e,f. Here, we measured a series of valence spectra using several photon energies spanning the Cooper minimum of the $\mathrm{Ag} 4 \mathrm{~d}$ states (i.e. photon energies from 150 to 230 and $350 \mathrm{eV}$ ). By observing how the relative intensities change with photon energy, one can identify which features are from Ag. The valence spectra in Figure 5e,f are normalized with respect to the intensity of the $\mathrm{Cu} 3 \mathrm{~d}$ peak (at ca. $3 \mathrm{eV}$ ). In the case of the pristine surface, the $\mathrm{Ag} 4 \mathrm{~d}$ states (at ca. 4-8 $\mathrm{eV}$ ) increase relative to the $\mathrm{Cu} 3 \mathrm{~d}$ states for photon energies away from the Cooper minimum. The spectra also show the absence of O-related peaks (which would be at $2 \mathrm{eV}$ ) at photon energies that are very sensitive to $\mathrm{O} 2 \mathrm{p}$ states (i.e. at $h \nu$ $=150 \mathrm{eV})$. These observations imply that the surface was metallic and contained only $\mathrm{Ag}$ and $\mathrm{Cu}$ within the field of view.

In contrast, the valence spectra of the oxidized surface are dominated by the $\mathrm{Cu} 3 \mathrm{~d}$ - and $\mathrm{O} 2 \mathrm{p}$-based features, with the $\mathrm{Ag}$ $4 \mathrm{~d}$ features having a substantial intensity only at photon energies far from the Cooper minimum. The line-shape of the spectrum at $h \nu=150 \mathrm{eV}$ is essentially the same as that observed under near-ambient pressure conditions using the same photon energy (Figure 2C).

A XPEEM spectromicroscopy map of the valence region was used to identify the spatial features seen in the LEEM image of the oxidized surface. Figure 6a shows the mapping of the $\mathrm{Cu}_{x} \mathrm{O}_{y}$ spectrum. Figure $6 \mathrm{~b}-\mathrm{c}$ shows spectra extracted from various regions of the map. A PCA of the 120000 spectra in the image stack showed that only two factors (i.e. spectroscopic entities/reference spectra) are required to adequately fit the experimental data through a linear combination of those factors. While PCA can indicate how many components are needed to fit the data, it cannot reveal what those components are. Thus, a subjective method was used to decide which spectra to use as reference spectra (i.e. 
basis vectors) to fit the measured spectra. The selected internal reference spectra correspond to metallic $\mathrm{AgCu}$ and $\mathrm{Cu}_{x} \mathrm{O}_{y}$, as shown in Figure $6 \mathrm{~b}-\mathrm{c}$. The orange spectrum in Figure $6 \mathrm{~b}$ represents the sum of all spectra extracted from the brightcolored regions in Figure 6a, and the blue spectrum in Figure $6 \mathrm{c}$ represents the sum of spectra from the dark regions in Figure 6a.

3.3. Further Spectroscopic Characteristics of $\mathrm{Cu}_{x} \mathrm{O}_{y}$. From the datasets shown so far, one cannot explicitly identify the atomic structure of the overlayer; so we gathered further spectroscopic data using in situ XPS and NEXAFS. Measurements were performed at $1 \times 10^{-5} \mathrm{mbar}_{2}$ and $300{ }^{\circ} \mathrm{C}$. The $\mathrm{Cu} 2 \mathrm{p}$ photoemission spectrum of $\mathrm{Cu}_{x} \mathrm{O}_{y}$ (Figure $7 \mathrm{a}$ ) reveals a binding energy of $932.35 \mathrm{eV}$, which is nearly indistinguishable from $\mathrm{Cu}_{2} \mathrm{O}$ (binding energy of $932.3 \mathrm{eV}$ ). ${ }^{12}$ The $\mathrm{Cu}$ LMM Auger spectrum in Figure $7 \mathrm{~b}$, however, shows that the overlayer's $\mathrm{Cu}$ LMM characteristics are significantly different from all reference spectra (metallic copper, $\mathrm{Cu}_{2} \mathrm{O}$ and $\mathrm{CuO}$ ). ${ }^{15}$ Furthermore, the $\mathrm{O} 1 \mathrm{~s}$ spectrum of $\mathrm{Cu}_{x} \mathrm{O}_{y}$ (binding energy of $529.5 \mathrm{eV})$ is between that of $\mathrm{CuO}$ and $\mathrm{Cu}_{2} \mathrm{O}$ and is comparable with previous reports of O-terminated copper single crystal surfaces. ${ }^{12}$ The $\mathrm{Ag} 3 \mathrm{~d}_{5 / 2}$ binding energy of 368.2 $\mathrm{eV}$ is indistinguishable from metallic silver. ${ }^{16}$

The $\mathrm{Cu} \mathrm{L} \mathrm{L}_{3}$-edge NEXAFS spectrum reveals a very distinct feature of the $\mathrm{Cu}_{x} \mathrm{O}_{y}$ structure (Figure 8a). While the lineshape resembles $\mathrm{Cu}_{2} \mathrm{O}$, the position of the absorption edge is shifted by $0.75 \mathrm{eV}$ toward lower photon energy. This large shift implies a substantial difference in properties between $\mathrm{Cu}_{x} \mathrm{O}_{y}$ and $\mathrm{Cu}_{2} \mathrm{O}$. To precisely determine the magnitude of this shift, we generated an internal standard by over-oxidized the sample (0.2 mbar $\mathrm{O}_{2}, 400{ }^{\circ} \mathrm{C}$ for $90 \mathrm{~min}$ ) until bulk $\mathrm{Cu}_{2} \mathrm{O}$ formed on the surface. This procedure allowed direct comparison of $\mathrm{Cu}_{x} \mathrm{O}_{y}$ and $\mathrm{Cu}_{2} \mathrm{O}$ (Figure $8 \mathrm{a}$ ). As discussed in detail in the Supporting Information (see S4), the shift is a result of the lack of a band gap in $\mathrm{Cu}_{x} \mathrm{O}_{y}$. DFT calculations of the DOS show that the oxide is electronically coupled to the underlying metal, giving rise to states at the Fermi level. The O K-edge NEXAFS (Figure $8 \mathrm{~b}$ ) of $\mathrm{Cu}_{x} \mathrm{O}_{y}$ resembles O-terminated $\mathrm{Cu}(111)$ surface, with features at 530.0 and $532.7 \mathrm{eV} .^{12}$ However, if an O-terminated $\mathrm{Cu}$-surface were the correct interpretation of the structure, the $\mathrm{Cu} \mathrm{L}_{3}$-edge NEXAFS spectrum should resemble metallic copper, which it not the case. In summary, we observe an $\mathrm{O} \mathrm{K}$-edge that resembles $\mathrm{O}$-terminated $\mathrm{Cu}$, and a $\mathrm{Cu}$ L-edge that resembles $\mathrm{Cu}_{2} \mathrm{O}$, but with a substantial shift (Figure 8b).

\section{DISCUSSION}

4.1. Candidate Structures. Copper's affinity for oxygen gives rise to adsorbate-driven surface segregation. ${ }^{17-21}$ Several oxides could potentially be formed. Previous ab-initio thermodynamics work identified three candidate structures likely formed on $\mathrm{AgCu}$ in an oxidizing atmosphere: ${ }^{21}$ (I) a chemisorbed oxygen species (Figure 9a); (II) $\mathrm{Cu}_{2} \mathrm{O}$-like structures including two different candidates that are of particular interest: $\mathrm{p} 2$ (Figure $9 \mathrm{~b}$ ) and $\mathrm{p} 4-\mathrm{OCu}_{3}$ (Figure 9c); and (III) a structure derived from $\mathrm{CuO}$ that we call $\mathrm{CuO}-1 \mathrm{~L}$ (Figure 9d). The thermodynamic stability of these surface structures depends on both the oxygen chemical potential $\left(\Delta \mu_{\mathrm{O}}\right)$ and the $\mathrm{Cu}$ solute concentration in the bulk of $\mathrm{AgCu}(111)$.

Because of the inherent error of DFT-based calculations, one cannot definitively identify the structure solely by the calculated energy. While the chemisorbed structure $\left(\mathrm{Cu}_{4} \mathrm{O}_{4}\right)$ is too high in energy to feasibly form, the $\mathrm{p} 2$ and $\mathrm{p} 4-\mathrm{OCu}_{3}$ structures are predicted to be the most stable, with an almost degenerate Gibbs surface free energy. ${ }^{10}$ Given the stability of these structures, and the fact that kinetics also plays a role in oxide formation, a variety of oxides could be expected to coexist, with a tendency to form bulk-like structures at higher $\mathrm{Cu}$ coverages and increasing $\Delta \mu_{\mathrm{O}}{ }^{10}$

The LEED patterns presented in Figures $4 \mathrm{a}$ and $5 \mathrm{~d}$ strongly suggest a $(2 \times 2)$ periodicity of the overlayer with respect to the $\mathrm{AgCu}(111)$ surface. Hence, the $(4 \times 4)$ periodicity of the $\mathrm{p} 4-\mathrm{OCu}_{3}$ structure is not observed, and we can discard this structure as a candidate. It should be emphasized that the $\mathrm{p} 2$ structure was proposed based on analogous systems (i.e. the " 44 " structure on $\mathrm{Cu}) .{ }^{10}$ However, given the energy error inherent to DFT calculations, the subtle structural features, such as the pseudo-registry observed here, are difficult to predict.

4.2. Further Selection of Structure Candidates. While the spectroscopic similarities to $\mathrm{Cu}_{2} \mathrm{O}$ suggests $\mathrm{p} 2$ or $\mathrm{p} 4-\mathrm{OCu}_{3}$ as likely candidates, further confirmation was obtained by comparing the measured valence spectra with simulated spectra based on DFT calculated DOS. In order to compare with experimental photoemission spectra, the calculated pDOS were scaled by the respective computed gas-phase photoionization cross sections $[\sigma(\mathrm{O} 2 \mathrm{p})=0.292$ and $\sigma(\mathrm{Cu} 3 \mathrm{~d})=$ 3.644 at the experimentally used photon energy of $h \nu=170$ $\mathrm{eV}$. An energy-dependent Lorentzian lifetime broadening was applied to the calculated DOS $(0.003 \mathrm{eV}$ broadening per eV). A three parameter Tougaard background was subtracted from the measured spectra to account for the inelastic scattering signal.

Figure 10a shows the measured spectra of $\mathrm{Cu}_{2} \mathrm{O}$ and $\mathrm{Cu}_{x} \mathrm{O}_{y}$. One can see that $\mathrm{Cu} 3 \mathrm{~d}$ band of $\mathrm{Cu}_{x} \mathrm{O}_{y}$ is narrower than $\mathrm{Cu}_{2} \mathrm{O}$ and is shifted toward higher binding energy. These same differences are reproduced by the DFT calculations of the $\mathrm{p} 2$ structure (Figure 10b). Not only are the peak position and the narrowness of the $\mathrm{Cu} 3 \mathrm{~d}$ states well reproduced, so too are the observed shifts of the $\mathrm{O} 2 \mathrm{p}$-related states (shoulder at ca. 1-2 $\mathrm{eV})$.

Chemisorbed oxygen $\left(\mathrm{Cu}_{4} \mathrm{O}_{4}\right)$ exhibits a somewhat similar $\mathrm{Cu} 3 \mathrm{~d}$ peak shape to the p2 structure (except for the substantially larger intensity at $6-8 \mathrm{eV}$ in the DOS of $\mathrm{Cu}_{4} \mathrm{O}_{4}$ ); however, $\mathrm{Cu}_{4} \mathrm{O}_{4}$ has a substantially higher energy than the $\mathrm{p} 2$ structure and is not considered a likely candidate for the observed phase.

Finally, the $\mathrm{CuO}-1 \mathrm{ML}$ structure exhibits a much broader feature in the valence band than seen for $\mathrm{Cu}_{x} \mathrm{O}_{y}$, similar to its structural analogue, bulk $\mathrm{CuO}$. The increased band width is due to the strong hybridization of $\mathrm{Cu} 3 \mathrm{~d}$ and $\mathrm{O} 2 \mathrm{p}$ states in $\mathrm{CuO}$, giving rise to the feature at $4-6 \mathrm{eV} .{ }^{15}$ From the partial DOS (Figure S5), one can see that the $\mathrm{O}$ states contribute more intensively over a wider energy range to the measurable photoemission signal as compared to the other candidate structures. The calculated DOS of the $\mathrm{CuO}-1 \mathrm{ML}$ structure candidate in combination with the absence of experimental evidence for $\mathrm{Cu}^{2+}$ in the $\mathrm{Cu} 2 \mathrm{p}$ core level spectrum (i.e. strong satellite structure) leads us to conclude that $\mathrm{CuO}-1 \mathrm{ML}$ is an unlikely candidate.

4.3. Structure Model. Based on the experimental evidence, the overlayer appears to be based on the p2 structure, however, with a subtle difference. As shown in Figure $5 \mathrm{~d}$, the LEED pattern of $\mathrm{Cu}_{x} \mathrm{O}_{y}$ exhibits a Moire pattern, suggesting that the overlayer is slightly incommensurate with 

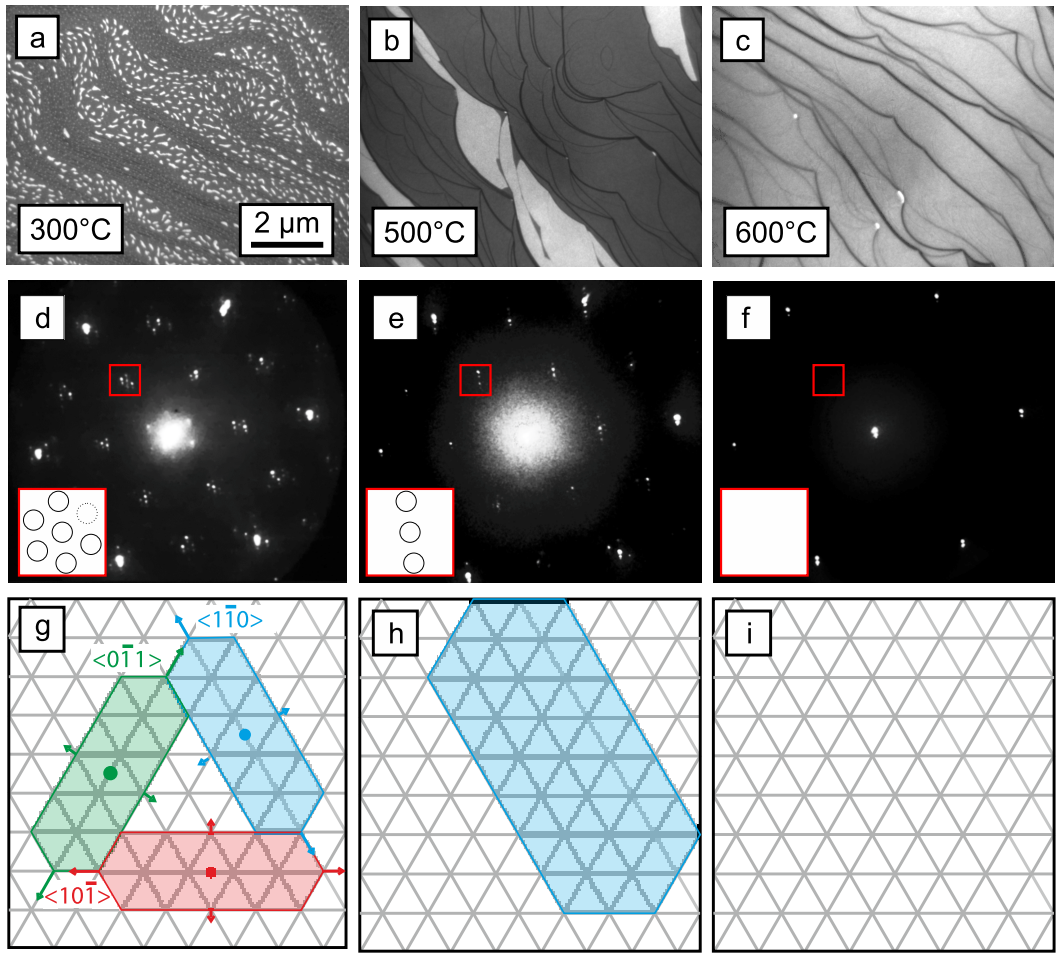

Figure 11. $(\mathrm{a}-\mathrm{c})$ LEEM images $\left(E_{\text {kin }}=16 \mathrm{eV}\right)$ measured at increasing annealing temperatures in $1 \times 10^{-5}$ mbar $\mathrm{O}_{2}$. (d-f) Corresponding LEED patterns from the images in $(\mathrm{a}-\mathrm{c})$. $(\mathrm{g}-\mathrm{i})$ Lattice models illustrating how the $\mathrm{Cu}_{x} \mathrm{O}_{y}$ islands nucleate, coalesce, and then decompose at increasing temperatures.

the $\operatorname{Ag}(111)$ surface. This observation could imply that the $\mathrm{Cu}_{x} \mathrm{O}_{y}$ structure is either expanded or compressed in all directions parallel to the $\mathrm{AgCu}(111)$ surface. However, an interesting change occurs upon annealing. When annealed to $500{ }^{\circ} \mathrm{C}$, the $\mathrm{Cu}_{x} \mathrm{O}_{y}$ domains coalesce into larger patches, and the diffraction pattern changes (see Figure 11a,b), such that the Moire spots no longer exhibit the three-fold symmetry of the substrate but rather a two-fold symmetry, as shown in Figure 11d,e. The fact that the Moire pattern becomes 2-fold symmetric after annealing implies that the expansion/ compression of the p2 lattice is actually only in one lattice direction and that the 6-fold Moiré pattern was a consequence of symmetry equivalent rotational domains.

Figure $11 \mathrm{~g}-\mathrm{i}$ depicts a structural model to explain the observed diffraction pattern changes with increasing temperatures. At $350{ }^{\circ} \mathrm{C}$, three distinct rotational domains nucleate on the surface, each with a pseudo- $(2 \times 2)$ structure, expanded or compressed relative to the substrate by $8 \%$ in the $\langle 1-10\rangle$ directions. The domains nucleate and grow until the fastgrowing direction intersects a neighboring domain. When domains meet, growth in the fast direction stops and only proceeds in the perpendicular directions, but slower. This growth mechanism can explain the observed surface morphology and LEED patterns seen in Figure 5c,d. When the surface-kinetically stuck in this state-is annealed, the kinetic barriers of surface diffusion are overcome, and the overlayer recrystallizes, with Ostwald ripening giving rise to a few large dominant rotational domains, as depicted in Figure 11b.

Calculated Gibb's free energies of compressed and expanded p2 lattices, having superstructures of $(12 \times 2),(13 \times 2)$, and $(14 \times 2)$ unit cell sizes relative to the $\operatorname{Ag}(111)$ surface (see Table S6), show that the $8 \%$ distortion is an expansion of the p2 lattice. The free energy minimum was found to be the (13 $\times 2)$ superstructure. An atomic model of the structure is shown in Figure 12. The $\mathrm{Cu}_{2} \mathrm{O}$-like lattice in the $(13 \times 2)$ structure

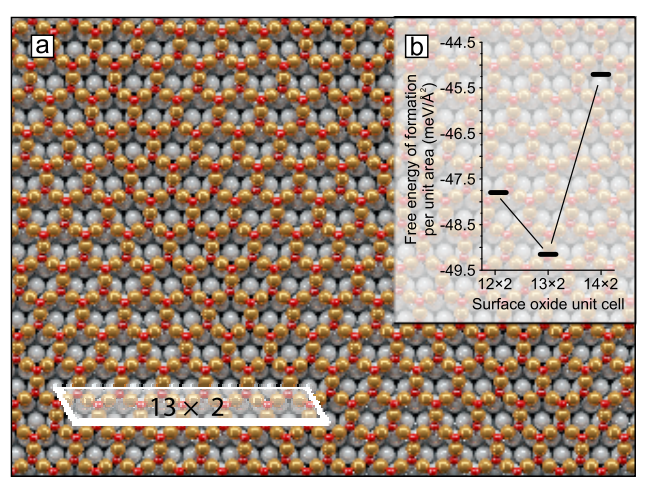

Figure 12. (a) Real space model of the overlayer oxide structure on the $\mathrm{AgCu}(111)$ surface. The $(13 \times 2)$ unit cell is indicated. $(\mathrm{b})$ Calculated free energy of formation for three overlayer unit cells with varying amounts of expansion in one direction.

has a $+4.1 \%$ strain in the $\langle 0-11\rangle$ direction and a strain of $-4.2 \%$ in the $\langle 01-1\rangle$ direction, relative to bulk $\mathrm{Cu}_{2} \mathrm{O}$. With this pseudo-commensurate overlayer structure, $\mathrm{Cu}$ atoms of the overlayer are situated in several coordination sites of the substrate (i.e., hollow, bridge, and top sites). Calculations in which the $\mathrm{p} 2$ structure is translated across the $\mathrm{Ag}$ into various coordination sites show that $\mathrm{Cu}$ in the $\mathrm{p} 2$ structure has almost no preference for a coordination site (Table S7), indicating a very weak interaction between the overlayer oxide and the metal surface.

4.4. Electronic Structure of the 2D-Oxide. The majority of the experimental and theoretical data indicate that the chemical state of the proposed $\mathrm{Cu}_{x} \mathrm{O}_{y}$ structure is similar to 
that of $\mathrm{Cu}_{2} \mathrm{O}$. The measured $\mathrm{Cu} 2 \mathrm{p}$ binding energies presented in Figure $7 \mathrm{a}$ only differ by $0.05 \mathrm{eV}$ compared to $\mathrm{Cu}_{2} \mathrm{O}$, and ground state DFT calculations show very similar initial-state energies of the two structures (Table S9). Moreover, Löwdin charge population analysis revealed both structures to have comparable charge densities (Table S10). However, the position of the $\mathrm{Cu}$ L-edge of the $\mathrm{Cu}_{x} \mathrm{O}_{y}$ structure is significantly different from $\mathrm{Cu}_{2} \mathrm{O}$, with the absorption edge of $\mathrm{Cu}_{x} \mathrm{O}_{y}$ being $0.75 \mathrm{eV}$ lower than $\mathrm{Cu}_{2} \mathrm{O}$ (Figure 8a). As elaborated in Supporting Information (see Figure S4), the reason for this shift is due to the lack of a band gap in the p2 structure when it is electronically coupled to the metallic substrate, as weak hybridization between the overlayer with the substrate gives rise to DOS across the Fermi level (see Figure S15). The white line shift seen in NEXAFS is not an indication of the charge on the $\mathrm{Cu}$ centers. In fact, all data suggest that the oxidation state of $\mathrm{Cu}$ in the $\mathrm{p} 2$ structure is very close to that of $\mathrm{Cu}$ in $\mathrm{Cu}_{2} \mathrm{O}$.

4.5. Comparison with Other Known Structures. There is a substantial body of knowledge about surface structures of $\mathrm{Cu}$ single crystals when exposed to low oxygen pressures. ${ }^{22-28}$ In general, there are two types of structure: (1) non-oxide like and (2) oxide-like monolayers. The type-1 structures consist of $\mathrm{O}$ ions bound to the $\mathrm{Cu}$ surface, where the translational symmetry of the $\mathrm{O}$ lattice does not resemble the O-sub-lattice of any copper oxide. In contrast, the type- 2 structures resemble a single lattice plane of $\mathrm{Cu}_{2} \mathrm{O}$ and can be thought of as $2 \mathrm{D}$ oxides. ${ }^{22,29,30}$ Because of the differences in the preferred $\mathrm{Cu}$ spacing of the oxide sub-lattice planes and the metallic $\mathrm{Cu}$ substrate, the oxide layers are quasi-epitaxial and exhibit interfacial strain with the underlying substrate. ${ }^{25}$

The $\mathrm{Cu}(100)$ and $\mathrm{Cu}(110)$ surfaces are only known to form type-1 structures. However, after large doses of oxygen, $\mathrm{Cu}_{2} \mathrm{O}$ nucleates on the surfaces and exhibits $3 \mathrm{D}$ growth. ${ }^{23,31}$ In contrast, the $\mathrm{Cu}(111)$ surface prefers to form an oxide-like 2D structure on its surface (with a meta-stable chemisorbed structure formed only within a narrow range of conditions). ${ }^{25}$ The $2 \mathrm{D}$ oxide that forms on $\mathrm{Cu}(111)$ is structurally analogous to the (111) plane of bulk $\mathrm{Cu}_{2} \mathrm{O}$.

The preference for non-oxide-like versus oxide-like structures is driven by the $\mathrm{Cu}-\mathrm{O}$ bond strength in the overlayer structure compared to the $\mathrm{O}$-substrate bond strength. For the $\mathrm{Cu}(100)$ and $\mathrm{Cu}(110)$ surfaces, the $\mathrm{Cu}$ atoms are not very densely packed, allowing for a high coordination to $\mathrm{O}$ ions, and consequently strong $\mathrm{Cu}-\mathrm{O}$ bonds. In contrast, the $\mathrm{Cu}(111)$ surface, which is densely packed, cannot provide high coordination to adsorbed $\mathrm{O}$ ions. Consequently, the $\mathrm{Cu}-\mathrm{O}$ bond to the $\mathrm{Cu}(111)$ surface is comparatively weak, and the $\mathrm{Cu}-\mathrm{O}$ bond in the $2 \mathrm{D}$ oxide is preferred.

To draw a comparison with the p2 structure on $\mathrm{AgCu}, \mathrm{O}$ forms a weak bond with $\mathrm{Ag}$ and prefers to be in a coordination environment surrounded by $\mathrm{Cu}$ ions. This preference drives $\mathrm{O}$ and $\mathrm{Cu}$ to form the oxide-like surface structure rather than a chemisorbed structure. However, the superstructure of the $2 \mathrm{D}$ oxide on $\mathrm{AgCu}$ exhibits a unit cell 13 times larger than the $\mathrm{Ag}(111)$ repeating unit, and only distorted in one crystallographic direction while the oxide-like layers on $\mathrm{Cu}(111)$, such as the "29" and " 44 " structures, exhibit unit cells that are 29times and 44-times larger than the $\mathrm{Cu}(111)$ repeating unit and are isotropic.

4.6. Relation to Ethylene Epoxidation. Previous works on ethylene epoxidation over silver catalysts have identified several adsorbed oxygen species present on Ag that could play a role in epoxidation ${ }^{32-36}$ The identities of these species are still debated in the literature, but the hypothesized species include chemisorbed, ordered O-ions, chemisorbed disordered O-ions, sub-surface species, and species from common impurities, such as $\mathrm{SiO}_{2}$ and $\mathrm{SO}_{x}{ }^{35,37-41}$

Under the conditions used in the present work to oxidize $\mathrm{AgCu}$, some regions of the surface remained non-oxidized (as seen in Figure 4). These regions consist of metallic $\mathrm{AgCu}$. The valence band spectra of these regions indicate that the metallic surface remains oxygen-free (there is no superstructure in the LEED pattern, and the valence band spectrum bears the signature of the clean alloy surface). Presumably, copper's much higher propensity for O compared to silver's caused any adsorbed $\mathrm{O}$ ions to be incorporated into the $\mathrm{Cu}_{x} \mathrm{O}_{y}$ film. ${ }^{21}$ However, at higher pressures, one would expect a more dynamic situation, where a steady-state population of adsorbed O species would develop on the metallic surface as well. Evidence of this assumption can be seen in the difference spectrum from NAP-XPS conditions of Figure 2B, where the metallic alloy spectrum exhibits some evidence of adsorbed $\mathrm{O}$ species (the feature at $1-2 \mathrm{eV}$ ). It is possible that at higher pressure, $\mathrm{O}$ ions could dynamically exchange between the $\mathrm{Cu}_{x} \mathrm{O}_{y}$ film, metallic surface, and ethylene.

Whether or not the $\mathrm{Cu}_{x} \mathrm{O}_{y}$ structure plays an active role in epoxidation is left up for debate, as a conclusive answer to this question is outside the scope of the present work. While the structure has previously been shown to be correlated with epoxide selectivity, ${ }^{4}$ theoretical work has also shown that epoxidation on the p2 structure would have a quite high activation barrier (calculated using DFT to be $1.49 \mathrm{eV}){ }^{42}$ Alternatively, the oxide could work as a source or sink for adsorbed $\mathrm{O}$-species on the metallic surface, giving rise to high population of selective $\mathrm{O}$-species or decrease in population of non-selective $\mathrm{O}$-species. Such a mechanism has been proposed to be the reason why small amounts of sulfur can enhance epoxide selectivity. ${ }^{41}$ Furthermore, the decomposition of $\mathrm{Cu}_{x} \mathrm{O}_{y}$ shown in the present work (Figure 11c) indicates that the $2 \mathrm{D}$ oxide is relatively unstable (compared to $\mathrm{Cu}_{2} \mathrm{O}$ ). Thus, it is quite possible that it plays an important role in populating the $\mathrm{Ag}$ surface with $\mathrm{O}$ ions.

\section{CONCLUSIONS}

We have experimentally determined that a two-dimensional meta-stable $\mathrm{Cu}_{x} \mathrm{O}_{y}$ surface oxide forms on $\mathrm{AgCu}$ alloys under ethylene epoxidation conditions using a combination of in situ, model and theoretical experiments. The structure is in essence a lattice plane of $\mathrm{Cu}_{2} \mathrm{O}$ placed on an $\mathrm{Ag}$ surface. It exhibits a copper oxidation state similar to $\mathrm{Cu}$ in $\mathrm{Cu}_{2} \mathrm{O}$; however, a weak coupling to the underlying metal affords its metallic properties. We thoroughly characterize the structure using XPEEM, LEED, UPS, XPS, and NEXAFS and compare the findings with DFT calculations. The structure is similar to the $\mathrm{p} 2$ structure previously predicted by Piccinin et al. ${ }^{21}$ but exhibits a pseudo-commensurate relationship with the underlying metal, with a unidirectional $8 \%$ expansion, relative to the underlying substrate.

The current study showcases the need of combining a multitude of experimental and theoretical approaches to elucidate the structures of a meta-stable species formed in reactive environments. A systematic linking of experimental results, by means of common attributes to bridge the pressure and complexity gap between individual approaches, enables the 
development of a valuable synergy between experiments and theory.

\section{ASSOCIATED CONTENT}

\section{(5) Supporting Information}

The Supporting Information is available free of charge at https://pubs.acs.org/doi/10.1021/acsami.0c03963.

Sample preparation data, outline of how datasets are connected, schematic to accompany the explanation of the observed NEXAFS peak position for the surface structure, calculated projected DOS for all surface structures discussed, calculated surface energies of strained overlayer structure, XPS and LEEM data of the overlayer structure when cooled in liquid nitrogen, calculated XPS binding energies and charge integrations from $\mathrm{Cu}_{2} \mathrm{O}, \mathrm{Cu}$ and the $\mathrm{p} 2$ structure, explanation of the PCA procedure used in the main text, compilation of known $\mathrm{O} 1 \mathrm{~s}$ binding energies for $\mathrm{Ag}-\mathrm{O}$ and $\mathrm{Cu}-\mathrm{O}$ systems, calculated projected DOS of a free-standing $\mathrm{p} 2$ film, and figure showing the lattice strain in $13 \times 2$ overlayer structure (PDF)

\section{AUTHOR INFORMATION}

\section{Corresponding Authors}

Kevin Schweinar - Department of Microstructure Physics and Alloy Design, Max-Planck-Institut für Eisenforschung GmbH, 40237 Düsseldorf, Germany; 이이. orcid.org/0000-0003-15952250; Email: k.schweinar@mpie.de

Mark T. Greiner - Department of Heterogeneous Reactions, Max-Planck Institute for Chemical Energy Conversion, 45470 Mülheim an der Ruhr, Germany; (1) orcid.org/0000-00024363-7189; Email: mark.greiner@cec.mpg.de

\section{Authors}

Sebastian Beeg - Department of Heterogeneous Reactions, MaxPlanck Institute for Chemical Energy Conversion, 45470

Mülheim an der Ruhr, Germany

Caroline Hartwig - Department of Heterogeneous Reactions, Max-Planck Institute for Chemical Energy Conversion, 45470 Mülheim an der Ruhr, Germany

Catherine R. Rajamathi - Department of Heterogeneous Reactions, Max-Planck Institute for Chemical Energy Conversion, 45470 Mülheim an der Ruhr, Germany

Olga Kasian - Department of Interface Chemistry and Surface Engineering, Max-Planck-Institut für Eisenforschung $\mathrm{GmbH}$, 40237 Düsseldorf, Germany; Helmholtz Zentrum Berlin für Materialien und Energie, 14109 Berlin, Germany; ๑ orcid.org/0000-0001-6315-0637

Simone Piccinin - CNR-IOM DEMOCRITOS, Istituto Officina dei Materiali, Consiglio Nazionale delle Ricerche, 34136 Trieste, Italy; 이이. orcid.org/0000-0002-3601-7141

Mauricio J. Prieto - Fritz-Haber-Institute of the Max-Planck Society, Department of Interface Science and Department of Chemical Physics, 14195 Berlin, Germany; (1) orcid.org/00000002-5087-4545

Liviu C. Tanase - Fritz-Haber-Institute of the Max-Planck Society, Department of Interface Science and Department of Chemical Physics, 14195 Berlin, Germany; O orcid.org/00000002-4177-5676

Daniel M. Gottlob - Fritz-Haber-Institute of the Max-Planck Society, Department of Chemical Physics, 14195 Berlin, Germany
Thomas Schmidt - Fritz-Haber-Institute of the Max-Planck Society, Department of Interface Science and Department of Chemical Physics, 14195 Berlin, Germany; 이이. ord/00000003-4389-2080

Dierk Raabe - Department of Microstructure Physics and Alloy Design, Max-Planck-Institut für Eisenforschung GmbH, 40237 Düsseldorf, Germany

Robert Schlögl - Department of Heterogeneous Reactions, MaxPlanck Institute for Chemical Energy Conversion, 45470 Mülheim an der Ruhr, Germany; Department of Inorganic Chemistry, Fritz-Haber Institute of the Max-Planck Society, 14195 Berlin, Germany

Baptiste Gault - Department of Microstructure Physics and Alloy Design, Max-Planck-Institut für Eisenforschung GmbH, 40237 Düsseldorf, Germany; Department of Materials, Imperial College London, Royal School of Mines, London SW7 2AZ, U.K.

Travis E. Jones - Department of Inorganic Chemistry, FritzHaber Institute of the Max-Planck Society, 14195 Berlin, Germany; 이이이.0rg/0000-0001-8921-7641

Complete contact information is available at: https://pubs.acs.org/10.1021/acsami.0c03963

\section{Funding}

Financial support by the Federal German Ministry of Education and Research (BMBF) under the contract 05 KS4WWB/4 as well as by the Max-Planck Society is gratefully acknowledged.

\section{Notes}

The authors declare no competing financial interest.

\section{ACKNOWLEDGMENTS}

The authors would like to thank HZB for the allocation of synchrotron radiation beamtime. K.S. is grateful for funding through the IMPRS-SurMat graduate school. Monika Nellessen and Katja Angenendt are acknowledged for their support in the metallography facilities at MPIE.

\section{REFERENCES}

(1) Norskov, J. K.; Abild-Pedersen, F.; Studt, F.; Bligaard, T. Density Functional Theory in Surface Chemistry and Catalysis. Proc. Natl. Acad. Sci. U.S.A. 2011, 108, 937-943.

(2) Nørskov, J. K.; Bligaard, T.; Rossmeisl, J.; Christensen, C. H. Towards the Computational Design of Solid Catalysts. Nat. Chem. 2009, 1, 37-46.

(3) Reuter, K.; Stampf, C.; Scheffler, M. Ab Initio Atomistic Thermodynamics and Statistical Mechanics of Surface Properties and Functions. In Handbook of Materials Modeling: Methods; Yip, S., Ed.; Springer Netherlands: Dordrecht, 2005; pp 149-194.

(4) Greiner, M. T.; Cao, J.; Jones, T. E.; Beeg, S.; Skorupska, K.; Carbonio, E. A.; Sezen, H.; Amati, M.; Gregoratti, L.; Willinger, M.G.; Knop-Gericke, A.; Schlögl, R. Phase Coexistence of Multiple Copper Oxides on $\mathrm{AgCu}$ Catalysts during Ethylene Epoxidation. ACS Catal. 2018, 8, 2286-2295.

(5) Linic, S.; Jankowiak, J.; Barteau, M. A. Selectivity Driven Design of Bimetallic Ethylene Epoxidation Catalysts from First Principles. J. Catal. 2004, 224, 489-493.

(6) Jankowiak, J.; Barteau, M. Ethylene Epoxidation over Silver and Copper-Silver Bimetallic Catalysts: I. Kinetics and Selectivity. J. Catal. 2005, 236, 366-378.

(7) Schmidt, T.; Marchetto, H.; Lévesque, P. L.; Groh, U.; Maier, F.; Preikszas, D.; Hartel, P.; Spehr, R.; Lilienkamp, G.; Engel, W.; Fink, R.; Bauer, E.; Rose, H.; Umbach, E.; Freund, H.-J. Double Aberration 
Correction in a Low-Energy Electron Microscope. Ultramicroscopy 2010, 110, 1358-1361.

(8) Schmidt, T.; Sala, A.; Marchetto, H.; Umbach, E.; Freund, H.-J. First Experimental Proof for Aberration Correction in XPEEM: Resolution, Transmission Enhancement, and Limitation by Space Charge Effects. Ultramicroscopy 2013, 126, 23-32.

(9) Krukau, A. V.; Vydrov, O. A.; Izmaylov, A. F.; Scuseria, G. E. Influence of the Exchange Screening Parameter on the Performance of Screened Hybrid Functionals. J. Chem. Phys. 2006, 125, 224106.

(10) Piccinin, S.; Stampfl, C.; Scheffler, M. Ag-Cu Alloy Surfaces in an Oxidizing Environment: A First-Principles Study. Surf. Sci. 2009, 603, 1467-1475.

(11) Giannozzi, P.; Baroni, S.; Bonini, N.; Calandra, M.; Car, R.; Cavazzoni, C.; Ceresoli, D.; Chiarotti, G. L.; Cococcioni, M.; Dabo, I.; Dal Corso, A.; de Gironcoli, S.; Fabris, S.; Fratesi, G.; Gebauer, R.; Gerstmann, U.; Gougoussis, C.; Kokalj, A.; Lazzeri, M.; MartinSamos, L.; Marzari, N.; Mauri, F.; Mazzarello, R.; Paolini, S.; Pasquarello, A.; Paulatto, L.; Sbraccia, C.; Scandolo, S.; Sclauzero, G.; Seitsonen, A. P.; Smogunov, A.; Umari, P.; Wentzcovitch, R. M. QUANTUM ESPRESSO: A Modular and Open-Source Software Project for Quantum Simulations of Materials. J. Phys.: Condens. Matter 2009, 21, 395502.

(12) Greiner, M. T.; Jones, T. E.; Johnson, B. E.; Rocha, T. C. R.; Wang, Z. J.; Armbrüster, M.; Willinger, M.; Knop-Gericke, A.; Schlögl, R. The Oxidation of Copper Catalysts During Ethylene Epoxidation. Phys. Chem. Chem. Phys. 2015, 17, 25073-25089.

(13) Hüfner, S.; Wertheim, G. K.; Smith, N. V.; Traum, M. M. XPS Density of States of Copper, Silver, and Nickel. Solid State Commun. 1972, 11, 323-326.

(14) Schön, G. ESCA Studies of $\mathrm{Cu}, \mathrm{Cu}_{2} \mathrm{O}$ and CuO. Surf. Sci. 1973, $35,96-108$.

(15) Ghijsen, J.; Tjeng, L. H.; van Elp, J.; Eskes, H.; Westerink, J.; Sawatzky, G. A.; Czyzyk, M. T. Electronic Structure of $\mathrm{Cu}_{2} \mathrm{O}$ and CuO. Phys. Rev. B 1988, 38, 11322-11330.

(16) Kaushik, V. K. XPS Core Level Spectra and Auger Parameters for some Silver Compounds. J. Electron Spectrosc. Relat. Phenom. 1991, 56, 273-277.

(17) Skriver, H. L.; Rosengaard, N. M. Surface Energy and Work Function of Elemental Metals. Phys. Rev. B 1992, 46, 7157-7168.

(18) Herron, J. A.; Mavrikakis, M. On the Composition of Bimetallic Near-Surface Alloys in the Presence of Oxygen and Carbon Monoxide. Catal. Commun. 2014, 52, 65-71.

(19) Kitchin, J. R.; Reuter, K.; Scheffler, M. Alloy Surface Segregation in Reactive Environments: First-Principles Atomistic Thermodynamics Study of $\mathrm{Ag}_{3} \mathrm{Pd}(111)$ in Oxygen Atmospheres. Phys. Rev. B 2008, 77, 075437.

(20) Han, B. C.; Van der Ven, A.; Ceder, G.; Hwang, B.-J. Surface Segregation and Ordering of Alloy Surfaces in the Presence of Adsorbates. Phys. Rev. B 2005, 72, 205409.

(21) Piccinin, S.; Stampfl, C.; Scheffler, M. First-Principles Investigation of Ag-Cu Alloy Surfaces in an Oxidizing Environment. Phys. Rev. B 2008, 77, 075426.

(22) Gattinoni, C.; Michaelides, A. Atomistic Details of Oxide Surfaces and Surface Oxidation: The Example of Copper and its Oxides. Surf. Sci. Rep. 2015, 70, 424-447.

(23) Lahtonen, K.; Hirsimäki, M.; Lampimäki, M.; Valden, M. Oxygen Adsorption-Induced Nanostructures and Island Formation on $\mathrm{Cu}\{100\}$ : Bridging the Gap Between the Formation of Surface Confined Oxygen Chemisorption Layer and Oxide Formation. J. Chem. Phys. 2008, 129, 124703.

(24) Judd, R. W.; Hollins, P.; Pritchard, J. The Interaction of Oxygen with $\mathrm{Cu}(111)$ : Adsorption, Incorporation and Reconstruction. Surf. Sci. 1986, 171, 643-653.

(25) Wiame, F.; Maurice, V.; Marcus, P. Initial Stages of Oxidation of $\mathrm{Cu}(111)$. Surf. Sci. 2007, 601, 1193-1204.

(26) Moritani, K.; Okada, M.; Teraoka, Y.; Yoshigoe, A.; Kasai, T. Reconstruction of $\mathrm{Cu}(111)$ Induced by a Hyperthermal Oxygen Molecular Beam. J. Phys. Chem. C 2008, 112, 8662-8667.
(27) Matsumoto, T.; Bennett, R. A.; Stone, P.; Yamada, T.; Domen, K.; Bowker, M. Scanning Tunneling Microscopy Studies of Oxygen Adsorption on $\mathrm{Cu}(111)$. Surf. Sci. 2001, 471, 225-245.

(28) Jensen, F.; Besenbacher, F.; Stensgaard, I. Two New Oxygen Induced Reconstructions on $\mathrm{Cu}(111)$. Surf. Sci. 1992, 269-270, 400404.

(29) Soon, A.; Todorova, M.; Delley, B.; Stampfl, C. Surface Oxides of the Oxygen-Copper System: Precursors to the Bulk Oxide Phase? Surf. Sci. 2007, 601, 5809-5813.

(30) Soon, A.; Todorova, M.; Delley, B.; Stampfl, C. Oxygen Adsorption and Stability of Surface Oxides on $\mathrm{Cu}(111)$ : A FirstPrinciples Investigation. Phys. Rev. B 2006, 73, 165424.

(31) Duan, X.; Warschkow, O.; Soon, A.; Delley, B.; Stampfl, C. Density Functional Study of Oxygen on $\mathrm{Cu}(100)$ and $\mathrm{Cu}(110)$ Surfaces. Phys. Rev. B 2010, 81, 075430.

(32) Williams, F. J.; Bird, D. P. C.; Palermo, A.; Santra, A. K.; Lambert, R. M. Mechanism, Selectivity Promotion, and New Ultraselective Pathways in Ag-Catalyzed Heterogeneous Epoxidation. J. Am. Chem. Soc. 2004, 126, 8509-8514.

(33) Su, D. S.; Jacob, T.; Hansen, T. W.; Wang, D.; Schlögl, R.; Freitag, B.; Kujawa, S. Surface Chemistry of Ag Particles: Identification of Oxide Species by Aberration-Corrected TEM and by DFT Calculations. Angew. Chem., Int. Ed. 2008, 47, 5005-5008.

(34) Xu, Y.; Greeley, J.; Mavrikakis, M. Effect of Subsurface Oxygen on the Reactivity of the $\mathrm{Ag}(111)$ Surface. J. Am. Chem. Soc. 2005, 127, 12823-12827.

(35) Bukhtiyarov, V.; Nizovskii, A.; Bluhm, H.; Havecker, M.; Kleimenov, E.; Knopgericke, A.; Schlogl, R. Combined in situ XPS and PTRMS Study of Ethylene Epoxidation over Silver. J. Catal. 2006, 238, 260-269.

(36) Bukhtiyarov, V. I.; Hävecker, M.; Kaichev, V. V.; Knop-Gericke, A.; Mayer, R. W.; Schlögl, R. Atomic Oxygen Species on Silver: Photoelectron Spectroscopy and X-Ray Absorption Studies. Phys. Rev. B 2003, 67, 235422.

(37) Rocha, T. C. R.; Oestereich, A.; Demidov, D. V.; Hävecker, M.; Zafeiratos, S.; Weinberg, G.; Bukhtiyarov, V. I.; Knop-Gericke, A.; Schlögl, R. The Silver-Oxygen System in Catalysis: New Insights by Near Ambient Pressure X-ray Photoelectron Spectroscopy. Phys. Chem. Chem. Phys. 2012, 14, 4554-4564.

(38) Carlisle, C. I.; Fujimoto, T.; Sim, W. S.; King, D. A. Atomic Imaging of the Transition between Oxygen Chemisorption and Oxide Film Growth on $\mathrm{Ag}\{111\}$. Surf. Sci. 2000, 470, 15-31.

(39) Bare, S. R.; Griffiths, K.; Lennard, W. N.; Tang, H. T. Generation of Atomic Oxygen on $\mathrm{Ag}(111)$ and $\mathrm{Ag}(110)$ using $\mathrm{NO}_{2}$ : A TPD, LEED, HREELS, XPS and NRA Study. Surf. Sci. 1995, 342, 185-198.

(40) Campbell, C. T. Atomic and Molecular Oxygen Adsorption on $\operatorname{Ag}(111)$. Surf. Sci. 1985, 157, 43-60.

(41) Jones, T. E.; Wyrwich, R.; Böcklein, S.; Carbonio, E. A.; Greiner, M. T.; Klyushin, A. Y.; Moritz, W.; Locatelli, A.; Menteş, T. O.; Niño, M. A.; Knop-Gericke, A.; Schlögl, R.; Günther, S.; Wintterlin, J.; Piccinin, S. The Selective Species in Ethylene Epoxidation on Silver. ACS Catal. 2018, 8, 3844-3852.

(42) Piccinin, S.; Nguyen, N. L.; Stampfl, C.; Scheffler, M. FirstPrinciples Study of the Mechanism of Ethylene Epoxidation over Ag$\mathrm{Cu}$ Particles. J. Mater. Chem. 2010, 20, 10521-10527. 